\title{
Comparison of Radiofrequency Ablation with or without Transcatheter Arterial Chemoembolization for Hepatocellular Carcinoma: A Meta- Analysis of Randomized Controlled Trials
}

\author{
Xinxin Wang \\ Gansu Provincial Hospital \\ Yang Che \\ Gansu Provincial Hospital \\ Shiyong Chen \\ Gansu Provincial Hospital \\ Biao Wu \\ Gansu Provincial Hospital \\ Yu He \\ Gansu Provincial Hospital \\ Baolong Dong \\ Gansu Provincial Hospital \\ Xiaojun Yang ( $\nabla$ yangxjmd@aliyun.com ) \\ Gansu Provincial Hospital
}

Research article

Keywords: hepatocellular carcinoma, transcatheter arterial chemoembolization, radiofrequency ablation, meta-analysis

Posted Date: April 5th, 2021

DOl: https://doi.org/10.21203/rs.3.rs-390558/v1

License: @ (i) This work is licensed under a Creative Commons Attribution 4.0 International License. Read Full License 


\section{Abstract \\ Background}

To evaluate the curative effect and safety of compare radiofrequency ablation (RFA) with or without transcatheter arterial chemoembolization (TACE) in the treatment of hepatocellular carcinoma (HCC)with the help of a meta-analysis of randomized controlled trials (RCTs) .

\section{Materials and Methods}

RCTs comparing TACE combined with RFA and RFA alone were searched electronically using PubMed, The Cochrane Library, and EMBASE. Fixed and random-effects were used to measure pooled estimates. Research indicators included overall survival (OS), recurrence-free survival (RFA), tumor progression and complications.

\section{Results}

Overall, 6 RCTs were included in this meta-analysis, with a total of 527 patients (TACE-RFA: 271; RFA: 256). 3- and5-year OS rate was higher in the TACE-RFA group than in the RFA group (OR $=1.74 ; 95 \% \mathrm{Cl}: 1.17-2.59 ; p=0.006 ; \mathrm{OR}=2.19 ; 95 \% \mathrm{Cl}: 1.49-3.22 ; p<0.0001)$. The 3- and 5-year RFS rate in the TACE-RFA group was higher than that in the RFA group (OR=1.92, 95\% Cl: $1.30 \sim 2.82, p=0.0009 ; 0 \mathrm{R}=1.81,95 \% \mathrm{Cl}$ : 1.21 2.70, $p=0.004$, respectively). The rate of tumor progression was lower in the TACE-RFA group than in the RFA group (OR $=0.57 ; 95 \% \mathrm{Cl}$ : $0.38 \sim 0.85 ; p=0.005)$. No significant differences in terms of 1-year OS rate and complications rate were observed between groups.

\section{Introduction}

$\mathrm{HCC}$ is the fifth most common cancer in the world and the second leading cause of cancer-related deaths [1]. Currently, the treatment of HCC includes not only surgical resection, liver transplantation, local ablative therapy and other single therapies, but also includes Multidisciplinary approach to treatment [2]. Hepatectomy is often a first-line treatment, but its efficacy is reduced by inadequate residual liver volume, poor liver reserve function and the presence of multiple nodules. Liver transplantation is another effective treatment, but it is limited by the source of donor liver and the choice of suitable patient [3]. RFA is the most commonly used local treatment method at present, especially for elderly patients with severe liver cirrhosis and other diseases. TACE is also one of the most commonly used methods for non-surgical treatment, it causes tumor cell necrosis, controls tumor cell growth, and reduces the toxicity of chemotherapy in normal tissues by injecting specific chemicals containing iodine oil mainly into the tumor area [4], so which it can slow the progression of the tumor and can be combined with targeted chemotherapy and ischemic necrosis caused by arterial embolization $[5,6]$. Driven by the current concept of multi-disciplinary treatment, the TACE-RFA is also a conventional treatment. Studies have shown that TACE-RFA in the treatment of $3 \sim 7 \mathrm{~cm}$ HCC is more effective than RFA alone [7]. Further, few systematic reviews and meta-analyses provide adequate evidence to prove the effect of TACE-RFA better than RFA in the treatment of HCC. Although the recent meta-analysis was reported by Jia-yan $\mathrm{Ni}$ el at had some clinical significance [8], it has a study was retracted which was included. In addition, given the recent increase in the number of publications of high-quality randomized controlled trials comparing the outcomes of TACE-RFA and RFA, it is necessary to combine data from these RCTs for a meta-analyses. Thus, in this study, we evaluate the curative effect and safety of TACE-RFA and RFA with the help of a meta-analysis of these RCTs.

\section{Material And Methods}

\section{Search strategy}

Full-text articles published between January 1983 and November 2020 were searched in PubMed, the Cochrane Library, and EMBASE. No limitations in terms of language of publication were applied. The following medical key words were used while searching: hepatocellular carcinoma, transcatheter arterial chemoembolization, and radiofrequency ablation. Besides, the references mentioned in the selected articles were also reviewed.

Inclusion and exclusion criteria

The studies that met the following inclusion criteria were included in this meta-analysis: (1) The patients were diagnosed with HCC; (2) The RCT compared TACE-RFA and RFA for the treatment of HCC; (3) HCC was performed in adult patients; and no metastases (4) Raw data was available for extraction about OS, RFS, tumor progression and complications. Further, the following studies were excluded: (1) studies that failed to meet any of the aforementioned points; (2) studies without data for retrieval; and (3) studies that did not report relevant data adequately.

Outcome definitions

The primary outcome of this study was the rate of overall survival (OS) rate, which was defined as the number of survival persons from the beginning of treatment to the last follow-up CT examination or death. With regard to secondary outcome, the rate of recurrence-free survival (RFS) rate was defined as the number of survival persons from the beginning of treatment to the last follow-up CT scan to examine the local progression of the tumor, 
new lesions in the liver, distant metastasis or death. The third outcome is tumor progression rate was defined as the number of persons about appearance of tumor enhancement or new lesions around the ablated area after treatment. Complications was defined as in the course of treatment, another or several diseases associated with TACE-RFA or RFA appear.

Data collection

Study selection and data extraction were performed by two reviewer independently based on the inclusion and exclusion criteria. Study reports included number of patients in each group, gender, mean age, OS, RFS, tumor progression and complications. Disagreements between reviewers were resolved by a discussion. The risk of bias graph and summary was used to analyze the quality of all RCTs.

Statistical analyses

Meta-analysis was performed using the Cochrane Collaboration software (RevMan version 5.3). The Cochran Q test was performed,at the same time, $\mathrm{I}^{2}$ value was used to quantitatively judge the heterogeneity. According to the criteria of Cochrane 5.3 : When $\mathrm{I}^{2}>50 \%$, the heterogeneity among studies is higher; When $25 \%<\mathrm{I}^{2} \leq 50 \%$, the heterogeneity among studies is lower;when $\mathrm{I}^{2} \leq 25 \%$, the heterogeneity among studies is lowest. In no significant heterogeneity $\left(I^{2} \leq 50 \%, P>0.1\right)$ was observed, a fixed-effects model was used; the random-effects model was used, when there has significant heterogeneity $\left(\mathrm{I}^{2}>50 \%, P \leq 0.1\right)$. The odds ratio (OR) with $95 \%$ confidence interval $(\mathrm{Cl})$ was calculated for dichotomous variables. Mean differences (MDs) were calculated for continuous variables. $P<0.05$ was considered significant difference.

\section{Results}

In all, 6 randomized controlled trials published as full-text articles were included in the study based on the inclusion and exclusion criteria. These studies included 271 patients who underwent TACE-RFA and 256 who underwent RFA in the treatment of hepatocellular carcinoma, five trials were patients with primary liver cancer and one was patients with recurrent liver cancer. The specific studies selecting process is shown in Fig. 1. The characteristics of the 6 included RCTs are shown in Table 2. The quality of these 6 trials is shown in Fig. 2.

Table 1

List of abbreviations

\begin{tabular}{|ll|}
\hline Full name & Abbreviations \\
\hline hepatocellular carcinoma & HCC \\
\hline radiofrequency ablation & RFA \\
\hline transcatheter arterial chemoembolization & TACE \\
\hline randomized controlled trials & RCTs \\
\hline overall survival & OS \\
\hline recurrence-free survival & RFA \\
\hline odds ratio & OR \\
\hline confidence interval & $\mathrm{Cl}$ \\
\hline
\end{tabular}


Table 2

The characteristics of 6 RCTs

\begin{tabular}{|c|c|c|c|c|c|c|c|c|c|c|c|c|}
\hline ID & Years & $\begin{array}{l}\text { Coun- } \\
\text { try }\end{array}$ & $\begin{array}{l}\text { Study } \\
\text { type }\end{array}$ & $\begin{array}{l}\text { Blind- } \\
\text { ing of } \\
\text { partici- } \\
\text { pants }\end{array}$ & $\begin{array}{l}\text { Type of } \\
\text { HCC }\end{array}$ & $\begin{array}{l}\text { Total case of } \\
\text { final } \\
\text { comparisons }\end{array}$ & $\begin{array}{l}\text { Cases } \\
\text { TACE- } \\
\text { RFA } \\
\text { /RFA }\end{array}$ & $\begin{array}{l}\text { Mean } \\
\text { age(y) } \\
\text { TACE-- } \\
\text { RFA /RFA }\end{array}$ & $\begin{array}{l}\text { Male\% } \\
\text { TACE- } \\
\text { RFA } \\
\text { /RFA }\end{array}$ & $\begin{array}{l}\text { HBsAg } \\
\text { positive } \\
\text { TACE- } \\
\text { RFA } \\
\text { /RFA }\end{array}$ & $\begin{array}{l}\text { Mean } \\
\text { tumor } \\
\text { size(cm) } \\
\text { TACE- } \\
\text { RFA /RFA }\end{array}$ & $\begin{array}{l}\text { Child- } \\
\text { Pugh } \\
\text { class } \\
\text { B/C } \\
\text { TACE- } \\
\text { RFA } \\
\text { /RFA }\end{array}$ \\
\hline $\begin{array}{l}\text { Peng el } \\
\text { at. }\end{array}$ & 2013 & China & $\begin{array}{l}\text { Rando- } \\
\text { mized } \\
\text { contr- } \\
\text { olled } \\
\text { trial, } \\
\text { Single } \\
\text { center } \\
\text { trial }\end{array}$ & $\begin{array}{l}\text { Single } \\
\text { blind }\end{array}$ & $\begin{array}{l}\text { Prim-ary } \\
\text { HCC }\end{array}$ & 189 & $94 / 95$ & $53.3 / 55.3$ & $75 / 71$ & $85 / 83$ & $3.47 / 3.39$ & $4 / 5$ \\
\hline $\begin{array}{l}\text { Peng el } \\
\text { at. }\end{array}$ & 2012 & China & $\begin{array}{l}\text { Rando- } \\
\text { mized } \\
\text { contro- } \\
\text { lled } \\
\text { trial, } \\
\text { Single } \\
\text { center } \\
\text { trial }\end{array}$ & $\begin{array}{l}\text { Single } \\
\text { blind }\end{array}$ & $\begin{array}{l}\text { Recurrence } \\
\text { HCC }\end{array}$ & 139 & $69 / 70$ & $57.5 / 55.1$ & $59 / 55$ & $63 / 65$ & unclear & $9 / 11$ \\
\hline $\begin{array}{l}\text { Shibata } \\
\text { el at. }\end{array}$ & 2009 & Japan & $\begin{array}{l}\text { Rando- } \\
\text { mized } \\
\text { contro- } \\
\text { lled } \\
\text { trial, } \\
\text { Single } \\
\text { center } \\
\text { trial }\end{array}$ & $\begin{array}{l}\text { Uncl- } \\
\text { ear }\end{array}$ & $\begin{array}{l}\text { Prim-ary } \\
\text { HCC }\end{array}$ & 89 & $46 / 43$ & $67.2 / 69.8$ & $31 / 33$ & $12 / 9$ & $1.7 / 1.6$ & $14 / 10$ \\
\hline $\begin{array}{l}\text { Yang el } \\
\text { at. }\end{array}$ & 2008 & China & $\begin{array}{l}\text { Rando- } \\
\text { mized } \\
\text { contro- } \\
\text { lled } \\
\text { trial, } \\
\text { Single } \\
\text { center } \\
\text { trial }\end{array}$ & $\begin{array}{l}\text { Uncl- } \\
\text { ear }\end{array}$ & $\begin{array}{l}\text { Prim-ary } \\
\text { HCC }\end{array}$ & 36 & $24 / 12$ & $59.1 / 61.0$ & $18 / 8$ & Unclear & $6.6 / 5.2$ & $6 / 7$ \\
\hline $\begin{array}{l}\text { Morimoto } \\
\text { el at. }\end{array}$ & 2010 & Japan & $\begin{array}{l}\text { Rando- } \\
\text { mized } \\
\text { contro- } \\
\text { Iled } \\
\text { trial, } \\
\text { Single } \\
\text { center } \\
\text { trial }\end{array}$ & $\begin{array}{l}\text { Uncl- } \\
\text { ear }\end{array}$ & $\begin{array}{l}\text { Prim-ary } \\
\text { HCC }\end{array}$ & 37 & $19 / 18$ & $70 / 73$ & $15 / 12$ & $17 / 16$ & $3.6 / 3.7$ & $1 / 2$ \\
\hline $\begin{array}{l}\text { Kang el } \\
\text { at. }\end{array}$ & 2007 & China & $\begin{array}{l}\text { Rand- } \\
\text { omized } \\
\text { contro- } \\
\text { Iled } \\
\text { trial, } \\
\text { Single } \\
\text { center } \\
\text { trial }\end{array}$ & $\begin{array}{l}\text { Uncl- } \\
\text { ear }\end{array}$ & $\begin{array}{l}\text { Prim-ary } \\
\text { HCC }\end{array}$ & 37 & $19 / 18$ & $52.2 / 50.7$ & $14 / 14$ & Unclear & $6.7 / 6.2$ & $7 / 6$ \\
\hline
\end{tabular}

Overall survival

Six studies including 527 patients reported 1-years OS rate [9-14]. There was no significant heterogeneity among the results $\left(I^{2}=0 \%, P=0.95\right)$. So a fixed-effects model was used. Meta-analysis showed the 1-year OS rate was higher in TACE-RFA group than in the RFA group,and this result has significant difference $(\mathrm{OR}=2.46 ; 95 \% \mathrm{Cl}: 1.37-4.39 ; p=0.002)$.

Five studies including 491 patients reported 3-year OS rate [9-11, 13-14]. The 3-year OS rate was 70.9\% (175/247) in the TACE-RFA group and 59.4\% $(145 / 244)$ in the RFA group. There was no significant heterogeneity among the results $\left(I^{2}=0 \%, P=0.51\right)$. So a fixed-effects model was used. Metaanalysis showed the result of comparison between TACE-RFA group and RFA group has significant difference $(\mathrm{OR}=1.74 ; 95 \% \mathrm{Cl}$ : $1.17-2.59 ; p=0.006)$.

Four studies including 454 patients reported 5-year OS rate $[9,11,12,14]$. The 5 -year OS rate was $62.3 \%$ (142/228) in the TACE-RFA group and 43.8\% $(99 / 226)$ in the RFA group. There was lower significant heterogeneity among the results $\left(I^{2}=28 \%, P=0.24\right)$. So a fixed-effects model was used. Meta- 
analysis showed the result of comparison between TACE-RFA group and RFA group has significant difference $(\mathrm{OR}=2.19 ; 95 \%$ Cl: $1.49-3.22 ; p<$ 0.0001). (Fig. 3)

Recurrence-free survival

Four studies including 454 patients reported 3-years RFS rate [9-11, 13]. The 3-year RFS rate was 49.6\% (113/228) in the TACE-RFA group and 34.5\% $(78 / 226)$ in the RFA group. There was lower significant heterogeneity among the results $\left(I^{2}=34 \%, P=0.21\right)$. So a fixed-effects model was used. Metaanalysis showed the result of comparison between TACE-RFA group and RFA group has significant difference $(\mathrm{OR}=1.92,95 \% \mathrm{Cl}: 1.30 \sim 2.82, p=$ 0.0009). (Fig. 3)

Moreover, three studies including 417 patients reported 5-years RFS rate $[9,10,11]$, and 5-year RFS rate was higher in the TACE-RFA group than in the RFA group. There was no significant heterogeneity among the results $\left(I^{2}=0 \%, P=0.95\right)$. So a fixed-effects model was used. Meta-analysis showed the result of comparison between TACE-RFA group and RFA group has significant difference (OR=1.81, 95\% Cl: $1.21 \sim 2.70, p=0.004)$. (Fig. 3)

Tumor progression

Five studies including 490 patients reported tumor progression rate [9-13]. The rate of tumor progression in TACE-RFA group and RFA group was 23.8\% $(60 / 252)$ and $35.3 \%(84 / 238)$, respectively. There was lower significant heterogeneity among the results $\left(I^{2}=44 \%, P=0.13\right)$. So a fixed-effects model was used. Meta-analysis showed there has significant difference in the TACE-RFA group than RFA group $(\mathrm{OR}=0.57 ; 95 \% \mathrm{Cl}: 0.38 \sim 0.85 ; p=0.005)$ (Fig. 4).

Complications

Five studies reported major complications after the treatment of TACE-RFA or RFA alone that have liver failure, persistent jaundice, gastric hemorrhage, ascites and so on[9-13]. However, one studies wasn't reported the specific number of patients who had complicantions ${ }^{[10]}$. Finally, this meta-analysis showed four studies about complications after two different treatment $[9,11-13]$, and the incidence rates of complications in the TACE-RFA and RFA groups were $2.61 \%(4 / 153)$ and $7.38 \%(11 / 149)$, respectively. There was higher significant heterogeneity among the results $\left(I^{2}=67 \%, P=0.03\right)$, so a random-effects model was used. Meta-analysis showed the rate of complication were similar after treatment TACE-RFA and RFA, there was no significant difference (Fig. 4).

\section{Discussion}

Although surgery is the preferred treatment for HCC, only 20\% 30 patients can be resected due to the fact that most of the patients with liver cancer have chronic cirrhosis, or most of the patients have reached the middle or advanced stage at the time of diagnosis. In recent years, the development of local ablative treatment make some patients with HCC who are not suitable for hepatectomy have the chance of radical treatment. Local ablative treatment is a kind of therapeutic methods to target tumor with the guidance of medical imaging technology and directly kill tumor tissues by local physical or chemical methods [2]. RFA is a minimally invasive treatment of HCC ablation method commonly used. Alternating Current induced heat from the radio frequency electrode tip up to $60 \sim 100^{\circ} \mathrm{C}$, When the tumor is exposed to this high temperature, clotting necrosis occurs almost immediately as an irreversible injury. Studies have shown that, in the absence of vascular, bile duct and adjacent organs invasion and distant metastasis, RFA has radical therapeutic effect for HCC patients whose liver function grade reaches Child-pugh A/B [15, 16]. However, tumor size has a significant impact on the efficacy of RFA. Livraghi T et al have shown that the postoperative necrosis rate of RFA is $60 \%$ for lesions with a maximum diameter of $3 \sim 5 \mathrm{~cm}$. The maximum tumor diameter $>5 \mathrm{~cm}$, the total tumor necrosis rate was only $24 \%$ [17], because it was difficult for the RFA range to completely cover the safe edge of the tumor when the tumor was large or had a special location. Some studies have also reported the long-term efficacy of RFA is very good which is used $\leq 2 \mathrm{~cm} \mathrm{HCC}$. Histopathologically, areas with well differentiated in $\leq 2 \mathrm{~cm}$ HCC are larger, with fewer satellite lesions and less portal vein invasion [18-20]. Multi-disciplinary treatment is highly regarded in recent years and treatment patterns, also contribute liver cancer diagnosis, entered the era of multidisciplinary multimodal coexist. The monotherapy method from the past, into a new model of joint application which including surgery, liver transplant, local ablation, TACE, radiotherapy, systemic chemotherapy, targeted therapy and so on.

The combination therapy of TACE and RFA has been gradually applied in the treatment of liver cancer. Jiang, F el at has shown that TACE-RFA can effectively control the growth of liver cancer lesions, reduce the level of tumor-related serum markers, and inhibit tumor cell activity [21], but Kim JW el at. have reported conflicting results which shown that the similar effective between TACE-RFA and RFA[22]. However, in this meta-analysis, we showed that the TACE-RFA group was associated with a higher 3-year or 5-year OS rate than the RFA group, and they have the significant difference. This is consistent with the outcomes reported in a recent meta-analysis [8], although the 1-year OS rate has no significant difference. This was consistent with the study by R. lezzi, M et al [23]. The reason of high OS rate after the treatment TACE-RFA as follows: Firstly, during the combined treatment, iodide precipitates around the lesion. Therefore, it can not only be used as a marker of RFA that making it easier for the operator to identify the ablation area, but also act as a thermal conduction medium to improve the ablation efficiency and keep the surrounding HCC microenvironment in a static state. By improving the ablation effect, tumor recurrence can be reduced [24]. Secondly, TACE can reduced heat loss during RFA by blocking blood flow into the tumor [25]. Thirdly, Chemotherapy-Cancer drugs increase the effect of high body temperature on cancer cells. Finally, TACE can further treat microlesions that cannot be detected by naked eye or imagings, thus improving the OS rate of patients. 
Tumor recurrence and progression are the major risk factors affecting the prognosis of HCC patients [26]. To the best of our knowledge, RFA is not a suitable treatment for greater nodular or multiple nodular tumors. Moreover, Nakashima $\mathrm{O}$ et al found early recurrence and multiple recurrent nodules are related to portal vein tumor thrombus [27]. TACE-RFA can effectively induce those nodular necrosis and improve the tumor necrosis rate, and chemotherapy-cancer drugs also has better curative effect on portal vein tumor thrombus. Our meta-analysis also shows that the 3-and 5-year RFS rate is higher in the TACE-RFA group than RFA group. And the tumor progression is also lower in the TACE-RFA group than RFA group.

Major complications of RFA include gastrointestinal perforation, biliary stenosis, bile leakage, tumor seeding, abscess formation, septicemia, peritonitis, cardiac arrest, pulmonary embolism, and left pneumothorax and so on[17]. The most common complications to TACE treatment mainly characterized by acute hepatic impairment, acute renal impairment, gastrointestinal bleeding, cholecystitis and gallbladder perforation, embolization agent ectopic embolization and so on. Liver failure after TACE is the main limitation of survival benefit. In a previous study, it happened to more than 50 percent of patients [28]. However, major complications after TACE-RFA are uncommon. In previous studies, TACE-RFA has been shown to be safe, with the incidence of major complications ranging from 0 to $2.2 \%[29,30]$. Our meta-analysis showed that the TACE-RFA group was associated with a lower incidence rate of complications than the RFA group, but it has no significant difference was shown by this study. We hypothesized that the combination of TACE and RFA might result in the simultaneous occurrence of two treatment-related complications. Finally, heterogeneity in the occurrence of major complications $\left(I^{2}=67 \%\right)$ may have resulted from of the use of different definitions among major complications.

The limitations of meta-analysis include the following: the studies are all from Asian populations, the number of included studies was limited, and the differences about Child-Pugh class, tumor size, number of tumors, tumor stage and so on was used. These factors may affect the reliability of the conclusion.

\section{Conclusion}

This study shows that TACE-RFA improves the rate of 3- and 5-year OS and RFS, and no significant difference in complication rates. Combined with clinical prognostic significance, we considered the TACE-RFA is superior to RFA alone, although further high-quality RCTs are still required for the validation of these results.

\section{Declarations}

Ethics approval and consent to participate

This manuscript is not reported studies involving human participants, human data or human tissue. So the "ethics approval and consent to participate" isn't appropriate for our manuscript.

Consent for publication

This manuscript doesn't contain any individual person's data in any form(including any individual details, images or videos). So the “Consent for publication" isn't appropriate for our manuscript.

Availability of data and materials

Full-text articles publishedwere searched in PubMed (https://pubmed.ncbi.nlm.nih.gov/) , The Cochrane Library (https://www.cochranelibrary.com ), and EMBASE (https://www.embase.com). And figures has made by the Cochrane Collaboration software RevMan version 5.3. So data sharing is not applicable to this article as no datasets were generated or analysed during the current study.

Competing interests

We confirm that the manuscript has been read and approved by all named authors and that there are no other persons who satisfied the criteria for authorship but are not listed. We further confirm that the order of authors listed in the manuscript has been approved by all of us that including the cofirst authors.

We also declare that they have no known competing financial interests or personal relationships that could have appeared to influence the work reported in this paper.

We understand that the Corresponding Author is the sole contact for the Editorial process. He is responsible for communicating with the other authors about progress, submissions of revisions and final approval of proofs.

Copyright and plagiarism

We declare that this manuscript is original, has not been published before and is not currently being considered for publication elsewhere.

Funding 
This work was supported by National Natural Science Foundation of China, No. 81660398; Hospital Key Program of National Scientific Research Cultivation Plan, No.19SYPYA-12. And the fundings can support the publication of this manuscript.

Authors' contributions

Xin-xin Wang: propose concepts, analyze statistics and write the manuscript; Yang Che: propose concepts and study selection; Shi-yong Chen: study selection and data extraction; Biao Wu: study selection and data extraction; Yu He: data extraction; Xiao-hua Dong: data extraction; Bao-long Dong: revision of the manuscript; Xiao-jun Yang: analyze statistics and revision of the manuscript.

Acknowledgements

I would like to extend my sincere gratitude to my supervisor, Xiaojun Yang, for his instructive advice and useful suggestion.

\section{References}

1. Torre LA, Bray F, Siegel RL. el al. Global cancer statistics, 2012. CA: a cancer journal for clinicians 2015, 65 (2), 87-108.

2. Guidelines for diagnosis and treatment of primary liver cancer in China. (2019 edition) [J]. Journal of Clinical Hepatology. 2020;36(02):277-92.

3. Yedibela S, Förtsch T, Hohenberger W, el al. Liver transplantation for hepatocellular carcinoma: A single European centre experience. Langenbeck's archives of surgery 2004, 389 (2), 104-109.

4. Ramsey DE, Kernagis LY, Soulen MC, Geschwind JF. Chemoembolization of hepatocellular carcinoma. Journal of vascular interventional radiology: JVIR. 2002;13(9 Pt 2):211-21.

5. Lo CM, Ngan H, Tso WK, el al. Randomized controlled trial of transarterial lipiodol chemoembolization for unresectable hepatocellular carcinoma. Hepatology 2002, 35 (5), 1164-71.

6. Takayasu K, Arii S, Ikai I, el al., Prospective cohort study of transarterial chemoembolization for unresectable hepatocellular carcinoma in 8510 patients. Gastroenterology 2006, 131 (2), 461-9.

7. Shibata $\mathrm{T}$, Isoda $\mathrm{H}$, Hirokawa Y, el al. Small hepatocellular carcinoma: is radiofrequency ablation combined with transcatheter arterial chemoembolization more effective than radiofrequency ablation alone for treatment? Radiology 2009, 252 (3), $905-913$.

8. Ni JY, Liu SS, Xu LF, el al. Meta-analysis of radiofrequency ablation in combination with transarterial chemoembolization for hepatocellular carcinoma. World Journal of Gastroenterology 2013, 19 (24), 3872-3882.

9. Shibata T, Isoda H, Hirokawa Y, el al. Small hepatocellular carcinoma: is radiofrequency ablation combined with transcatheter arterial chemoembolization more effective than radiofrequency ablation alone for treatment? Radiology 2009, 252 (3), $905-913$.

10. Peng ZW, Zhang YJ, Chen MS, el al. Radiofrequency ablation with or without transcatheter arterial chemoembolization in the treatment of hepatocellular carcinoma: a prospective randomized trial. Journal of clinical oncology 2013, 31 (4), 426-432.

11. Peng ZW, Zhang YJ, Liang HH, el al. Recurrent hepatocellular carcinoma treated with sequential transcatheter arterial chemoembolization and RF ablation versus RF ablation alone: a prospective randomized trial. Radiology 2012, 262 (2), 689-700.

12. Yang $P$, Liang M, Zhang Y. el al. Clinical application of a combination therapy of lentinan, multi-electrode RFA and TACE in HCC. Advances in therapy 2008, 25 (8), 787-794.

13. Morimoto M, Numata K, Kondou M, el al. Midterm outcomes in patients with intermediate-sized hepatocellular carcinoma: a randomized controlled trial for determining the efficacy of radiofrequency ablation combined with transcatheter arterial chemoembolization. Cancer 2010, 116 (23), 545260 .

14. Kang CB, Xu HB, Wang SL. el al. Treatment of large hepatoma by TACE in combination with RFA. Chinese Journal of Hepatobiliary Surgery. 2007; 13:828-30.

15. Chen MS, Li JQ, Zheng Y, el al. A prospective randomized trial comparing percutaneous local ablative therapy and partial hepatectomy for small hepatocellular carcinoma. Annals of surgery 2006, 243 (3), 321-8.

16. Feng K, Yan J, Li X, el al. A randomized controlled trial of radiofrequency ablation and surgical resection in the treatment of small hepatocellular carcinoma. Journal of hepatology 2012, 57 (4), 794-802.

17. Livraghi T, Goldberg SN, Lazzaroni S. el al. Hepatocellular carcinoma: radio-frequency ablation of medium and large lesions. Radiology. 2000;214(3):761-8.

18. Livraghi T, Meloni F, Di Stasi M, Rolle E, Solbiati L, Tinelli C, et al. Sustained complete response and complications rates after radiofrequency ablation of very early hepatocellular carcinoma in cirrhosis: Is resection still the treatment of choice? Hepatology. 2008;47(1):82-9.

19. Wang JH, Wang CC, Hung CH, Chen CL, Lu SN. Survival comparison between surgical resection and radiofrequency ablation for patients in BCLC very early/early stage hepatocellular carcinoma. Journal of hepatology. 2012;56(2):412-8.

20. Livraghi T. Single HCC smaller than $2 \mathrm{~cm}$ : Surgery or ablation - Interventional oncologist's perspective. J Hepato-Biliary-Pancreat Sci. 2010;17(4):425-9.

21. Jiang FQ, Lu W, Yang C, el al. Curative effect of transcatheter arterial chemoembolization combined with radiofrequency ablation in treating hepatic cell carcinoma and its effect on serum markers. Cancer biomarkers 2017, 20 (1), 17-22.

Page $7 / 11$ 
22. Kim JW, Kim JH, Won HJ, el al.Hepatocellular carcinomas $2-3 \mathrm{~cm}$ in diameter: transarterial chemoembolization plus radiofrequency ablation vs. radiofrequency ablation alone. European journal of radiology 2012, 81 (3), e189-93.

23. lezzi R, Pompili M, Posa A, Coppola G, Gasbarrini A, Bonomo L. Combined locoregional treatment of patients with hepatocellular carcinoma: State of the art. World J Gastroenterol. 2016;22(6):1935-42.

24. Tamai T, Oshige A, Tabu K, el al. Utility of percutaneous radiofrequency ablation alone or combined with transarterial chemoembolization for early hepatocellular carcinoma. Oncology Letters 2017, 14 (3), 3199-3206.

25. Bholee AK, Peng K, Zhou Z, el al. Radiofrequency ablation combined with transarterial chemoembolization versus hepatectomy for patients with hepatocellular carcinoma within Milan criteria: a retrospective case-control study. Clinical \& translational oncology: official publication of the Federation of Spanish Oncology Societies and of the National Cancer Institute of Mexico 2017, 19 (7), 844-852.

26. Peng ZW, Chen MS, Liang HH, el al. A case-control study comparing percutaneous radiofrequency ablation alone or combined with transcatheter arterial chemoembolization for hepatocellular carcinoma. European journal of surgical oncology: the journal of the European Society of Surgical Oncology and the British Association of Surgical Oncology 2010, 36 (3), 257 - 63.

27. Nakashima O, Kojiro M. Recurrence of hepatocellular carcinoma: multicentric occurrence or intrahepatic metastasis? A viewpoint in terms of pathology. J Hepato-biliary-Pancreat Surg. 2001;8(5):404-9.

28. A comparison of lipiodol. chemoembolization and conservative treatment for unresectable hepatocellular carcinoma. N Engl J Med. 1995;332(19):1256-61.

29. Veltri A, Moretto P, Doriguzzi A, el al. Radiofrequency thermal ablation (RFA) after transarterial chemoembolization (TACE) as a combined therapy for unresectable non-early hepatocellular carcinoma (HCC). European radiology 2006, 16 (3), 661-9.

30. Kagawa T, Koizumi J, Kojima S, el al. Transcatheter arterial chemoembolization plus radiofrequency ablation therapy for early stage hepatocellular carcinoma: comparison with surgical resection. Cancer 2010, 116 (15), 3638-44.

\section{Figures}

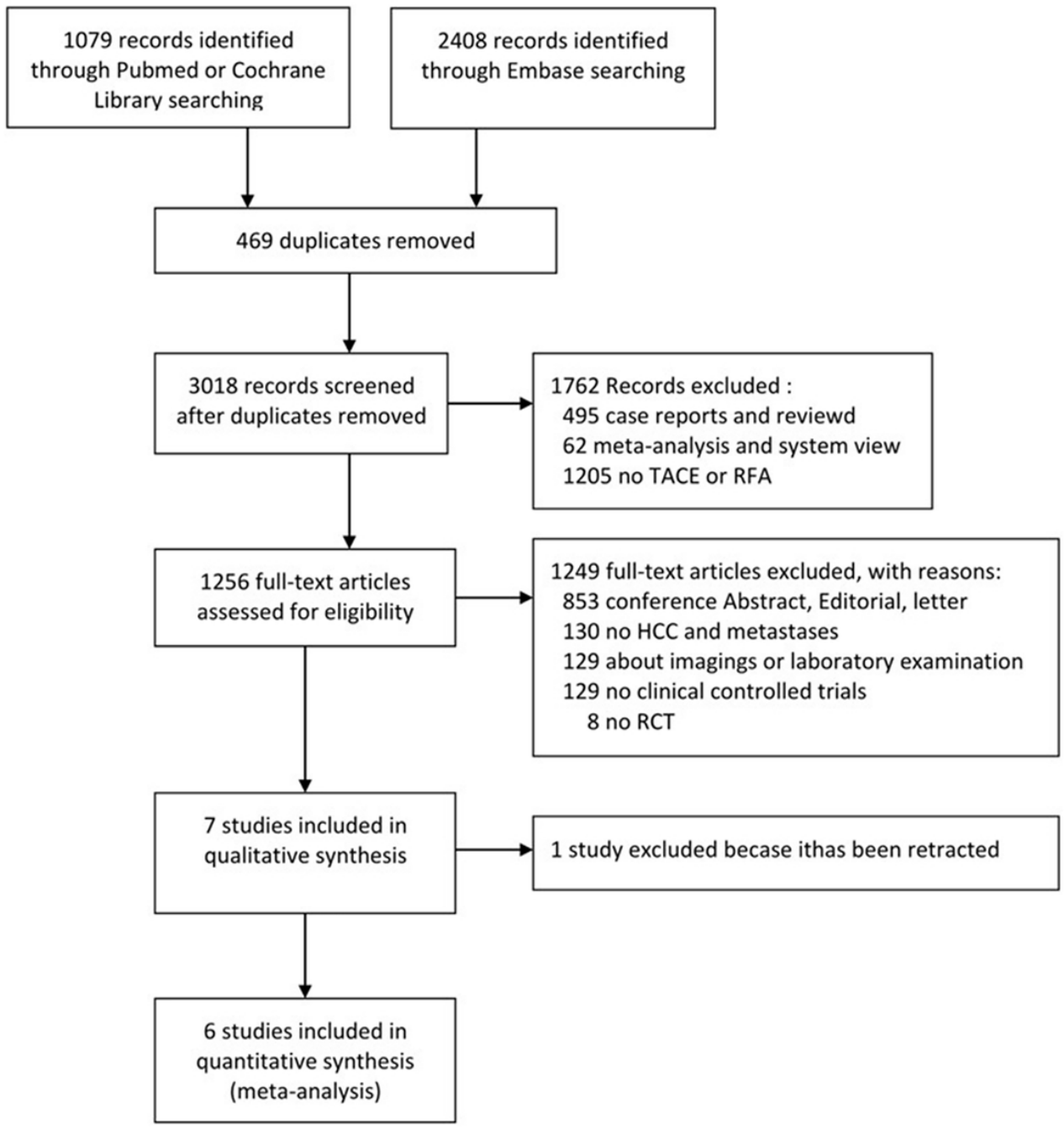

Page $8 / 11$ 
Figure 1

Screening flow chart for the include studies.

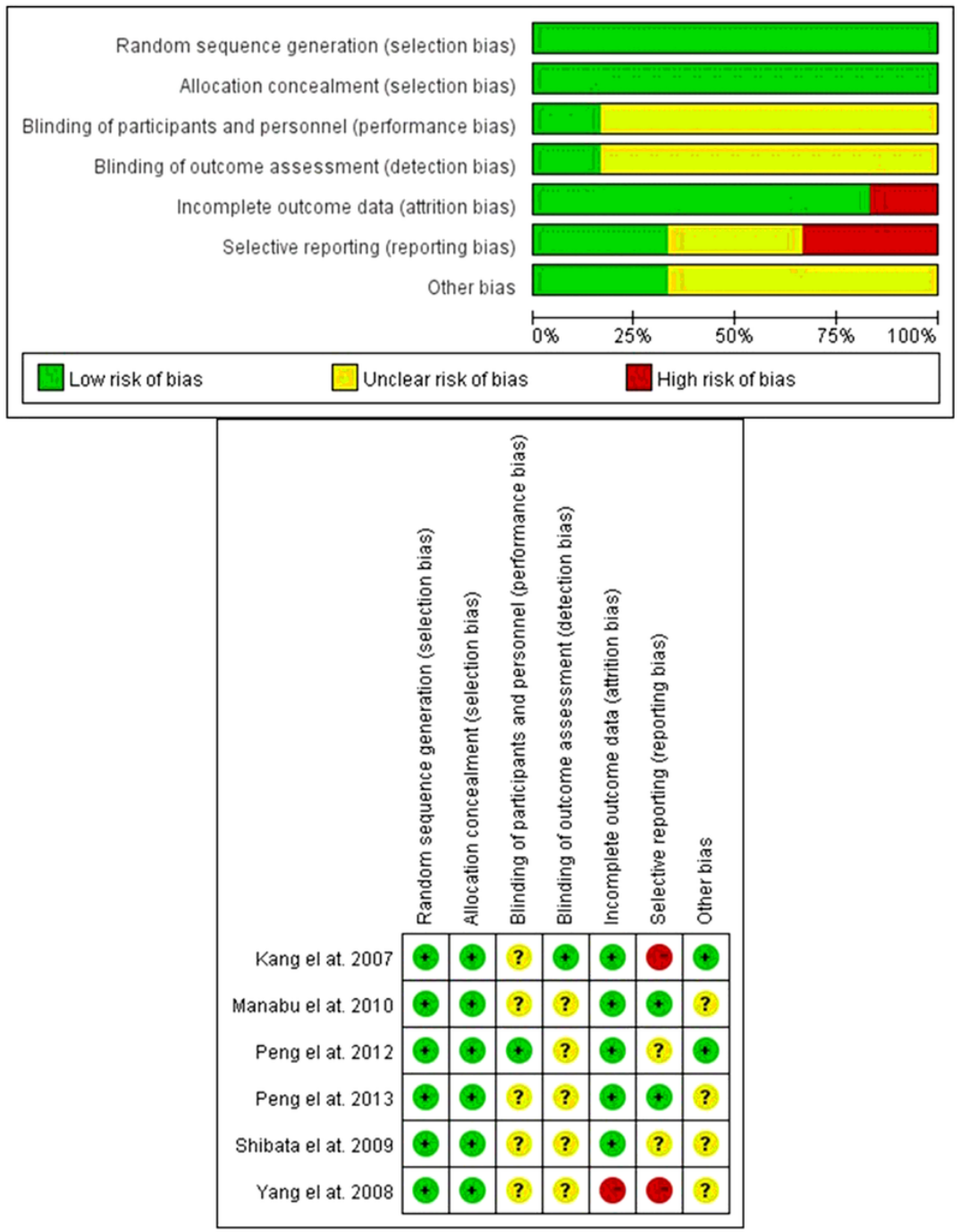

Figure 2

The quality of these 6 trials. The risk of bias graph and summary. 


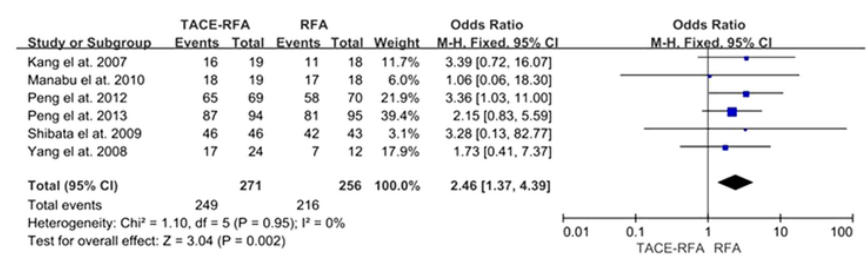

A

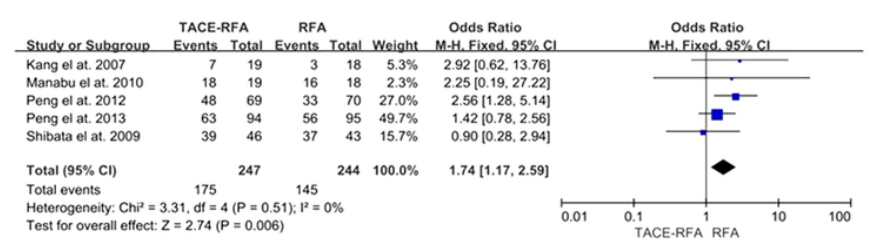

B

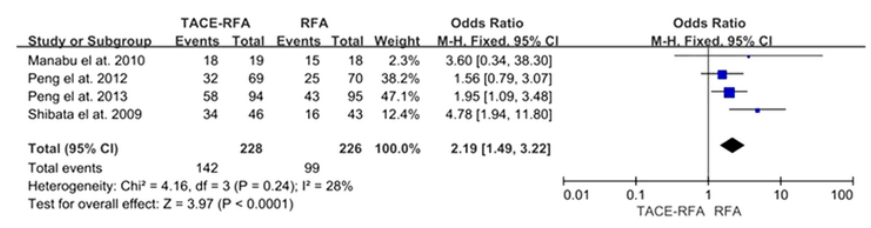

C

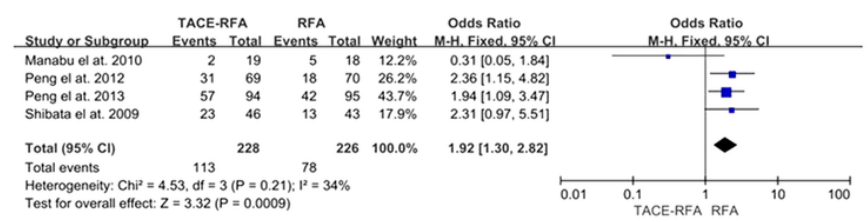

D

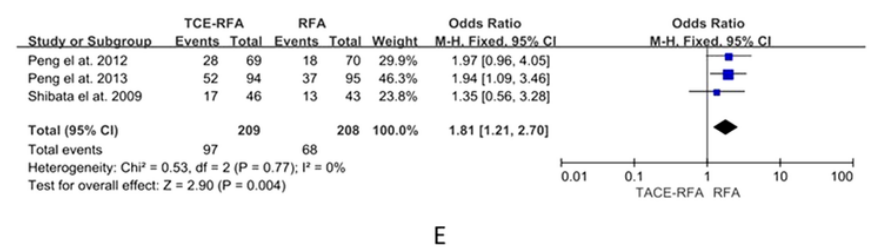

\section{Figure 3}

Comparison of OS and RFS rate between TACE-RFA and RFA group. A, B, C: the 1-, 3- and 5-year overall survival rate; D, E: the 3- and 5-year recurrencefree survival rate. 


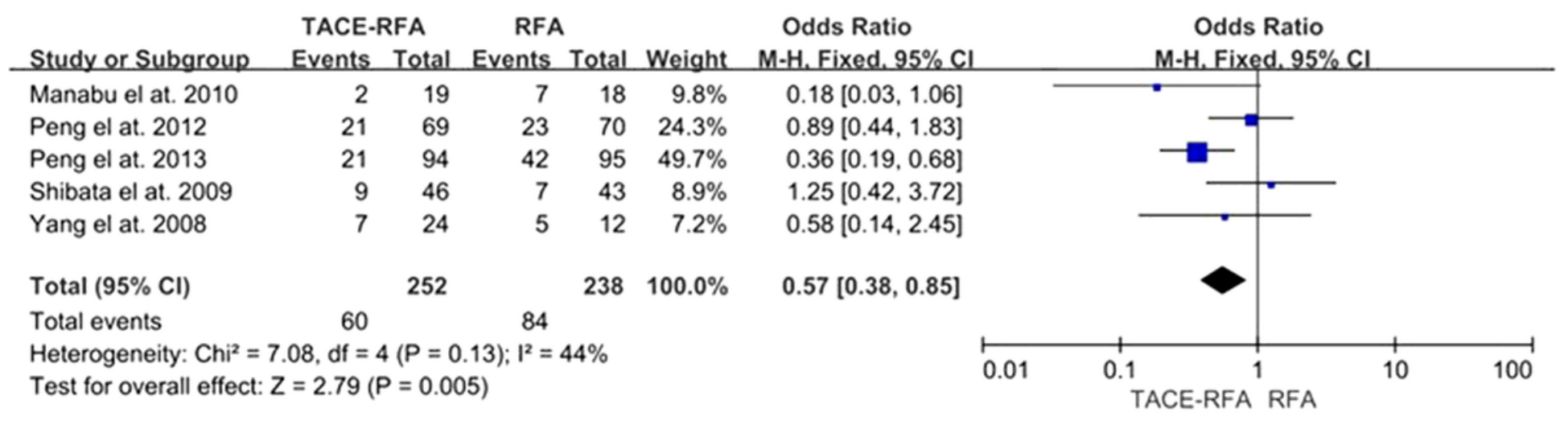

A

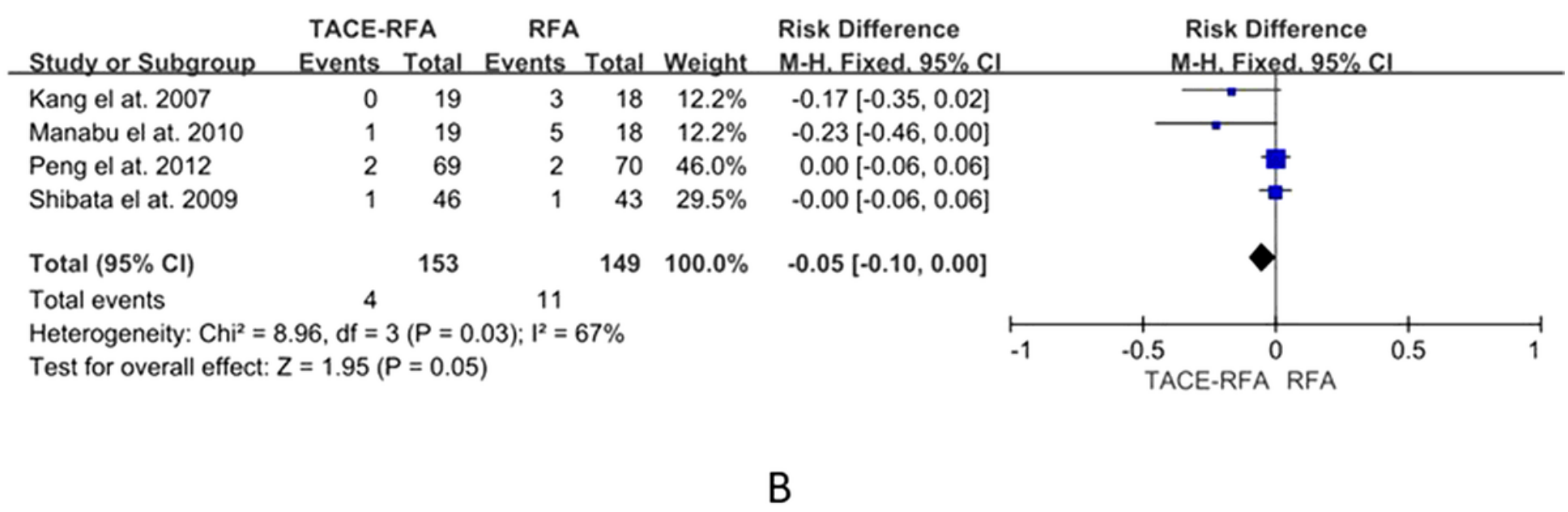

Figure 4

Comparison of tumor progression and complications rate between TACE-RFA and RFA group. A: the tumor progression rate; B: the complications rate.

\section{Supplementary Files}

This is a list of supplementary files associated with this preprint. Click to download.

- prisma2009checklist.doc 